\title{
Cadmium Stannates Synthesis via Thermal Treatment of Coprecipitated Salts
}

\author{
Andrey V. Sidorak, Viktor V. Ivanov, Alexander A. Shubin \\ Siberian Federal University, Svobodniy, Russia. \\ Email: Ashubin@sfu-kras.ru \\ Received March 21 ${ }^{\text {st }}, 2011$; revised April 29 $9^{\text {th }}, 2011$; accepted June $2^{\text {nd }}, 2011$.
}

\begin{abstract}
Cadmium meta- and orthostannate were synthesized by thermal treatment using the coprecipitation method. Tin (IV) chloride, cadmium acetate were used as the initial components, the ammonium carbonate was a precipitant. The coprecipitated compounds and the thermolysis products were analyzed by TGA/DSC methods, the thermal treatment samples were studied by XRD and SEM. The formation of proper products in soft thermal treatment conditions was confirmed. The stannates formation in terms of submicron sized particles was observed by microscopial investigation.
\end{abstract}

Keywords: Cadmium Metastannate, Cadmium Orthostannate, Chemical Precipitation, Powders, Thermolysis, Synthesis

\section{Introduction}

$\mathrm{CdSnO}_{3}$ и $\mathrm{Cd}_{2} \mathrm{SnO}_{4}$ cadmium stannates are interesting due to their optical and electrical properties. These compounds, related to so-called optically limpid conductive oxides, are used as thin films which are transparent in visible spectrum part [1], in semiconductor technology [2], as sensitive elements of chemical sensors [3-5] etc.

Different ways of stannates obtaining are used depending on a purpose. Thin films are prepared by means of aerosol of cadmium and tin compounds solutions composition pyrolysis [6], substrate covering with metalorganic compounds followed their thermolysis [7], sodium stannate and water-soluble cadmium salt ion-exchanging reaction [8], etc. For stoichiometric products powders obtaining the conventional method of solidphase synthesis from prepared powder oxides $[5,9,10]$ is used. The method is simple but rather time-consumimg because of the necessity to perform some intermediate mechanical grinds and also requires high temperatures and long time of synthesis. Such product is not optimal e.g. for electroconductive composite materials technologies because they require high dispersibility and statisticcally homogeneous stannate phase distribution [11]. Stannate synthesis of fine-grained form with soft temperature conditions and of short duration is desirable for electroconductive composite materials technologies.

Evidently there is no data for kinetics of cadmium stannates synthesis. We can meet with some descriptions of syntheses e.g. in $[9,12,13]$ : they are carried out in the open air under 1073 - $1273 \mathrm{~K}$ temperature range using long stepped anneals for volatile cadmium oxide loss reduction. On the other hand it is well known that high dispersibility of initial powder components substantially accelerates kinetics and decreases the temperature of efficient solid-phase synthesis. It also concerns the examined compounds [14].

Thus, the work is devoted to study the potential of cadmium meta- and orthostannate powder forms synthesis under low temperatures by means of thermal treatment of tin and cadmium thermally unstable salts coprecipitated composition.

\section{Experimental Part}

The decomposition of thermally unstable salts-precursors to obtain $\mathrm{CdSnO}_{3}$ and $\mathrm{Cd}_{2} \mathrm{SnO}_{4}$ was used. The powder precursors with $\mathrm{Cd}: \mathrm{Sn}$ molar ratios 1:1 and 1:2 were prepared by a chemical coprecipitation. Analytically pure reagents of $\mathrm{SnCl}_{4} \cdot 5 \mathrm{H}_{2} \mathrm{O}, \mathrm{Cd}\left(\mathrm{CH}_{3} \mathrm{COO}\right)_{2} \cdot 2 \mathrm{H}_{2} \mathrm{O}$ and $\left(\mathrm{NH}_{4}\right)_{2} \mathrm{CO}_{3}$ were used as starting materials. Solutions with $0.1 \mathrm{~mol} / \mathrm{L}$ tin and cadmium salts, in stoichiometric ratios 1:1 and 2:1, for $\mathrm{CdSnO}_{3}$ and $\mathrm{Cd}_{2} \mathrm{SnO}_{4}$, accordingly, were mixed and then a $0.2 \mathrm{~mol} / \mathrm{L}$ solution $\left(\mathrm{NH}_{4}\right)_{2} \mathrm{CO}_{3}$ was added. White fine-grained precipitates, dried for 10 $\mathrm{h}$ at temperature $383 \mathrm{~K}$. Further products were calcinated in the open air at $783,873,973,1073,1173,1223 \mathrm{~K}$ for an hour.

Thermal, XRD, elemental and microscopic analyses of obtained samples were carried out at different stages. 
Elemental analysis was performed by means of XRF using the ARL Advant'X (Thermo) spectrometer (Joint Use Center SFU) with an Rh anode X-ray tube. Quantitative elements content was evaluated by fundamental parameter method using the UniQuant 5. Thermal decomposition processes of precipitates were studied by thermogravimetry (TG) and differential scanning calorimetry (DSC) methods using the synchronous thermal analysis STA Jupiter 449C (Netzsch) device (heating rate 10 $\mathrm{K} / \mathrm{min}$ in flowing Ar atmosphere and a corundum crucible).

Thermal treatment products were studied by an X'Pert-Pro (PANalytical) X-ray diffractometer (XRD) with monochromatized $\mathrm{Cu} \mathrm{K} \alpha$ radiation $\left(\lambda_{1}=0.15406\right)$. The angular $2 \theta$ range of registration was from $5^{\circ}$ to $80^{\circ}$ with the step of $0.026^{\circ}$. Micrographs were obtained using a JEOL JSM-7001F scanning electron microscope (Joint Use Center SFU).

\section{Results and Discussion}

\subsection{Thermal Analysis of Precipitated Salt Mixtures}

The thermal behavior of Precipitated salts was investigated to obtain typical temperature intervals of the thermolysis. The TG and DSC curves for mixtures of $\mathrm{CdSnO}_{3}$ and $\mathrm{Cd}_{2} \mathrm{SnO}_{4}$ proper compositions are presented in Figure 1. TG-curves are substantially different: $\mathrm{CdSnO}_{3}$ mixture has two defined stages of weight loss and $\mathrm{Cd}_{2} \mathrm{SnO}_{4}$ mixture has only one. The first stage begins at the temperature of about $375 \mathrm{~K}$ and finishes at $\sim 650 \mathrm{~K}$ for both systems. We can notice the overlapping of some thermal effects within this temperature range. First of all the crystal water loss and cadmium carbonate decomposition are possible during the process:

$$
\mathrm{CdCO}_{3}=\mathrm{CdO}+\mathrm{CO}_{2}
$$

The authors [15] recorded the intensive peak of precipitated cadmium carbonate decomposition at the temperature of $623 \mathrm{~K}$. Our data are in accordance with their values.

For $\mathrm{CdSnO}_{3}$ precursors the second stage of weight loss is observed in the range $780 \mathrm{~K}$ to $950 \mathrm{~K}$. It is probably caused by tin (IV) compounds decomposition. It is well known that during the tin (IV) precipitation from water solutions the $\alpha$-stannic acid $\mathrm{SnO}_{2} \cdot \mathrm{nH}_{2} \mathrm{O}$ is formed ( $\mathrm{n}$ is closed to 1.8) [16]. Makeup precipitated $\alpha-\mathrm{SnO}_{2} \cdot \mathrm{nH}_{2} \mathrm{O}$ is an $\mathrm{X}$-ray amorphous phase but ageing and heating lead to water loss. Thus $\alpha-\mathrm{SnO}_{2} \cdot \mathrm{nH}_{2} \mathrm{O}$ turns into $\beta-\mathrm{SnO}_{2} \cdot \mathrm{nH}_{2} \mathrm{O}$ $(\mathrm{n}<0.4)$, which then detaches the rest of water step-bystep and crystallizes in $\mathrm{SnO}_{2}$ form. This process finishes at $870 \mathrm{~K}$ [17]. Our results of weight loss value and temperature range correlate to the mentioned above. The absence of significant weight loss for $\mathrm{Cd}_{2} \mathrm{SnO}_{4}$ precursors

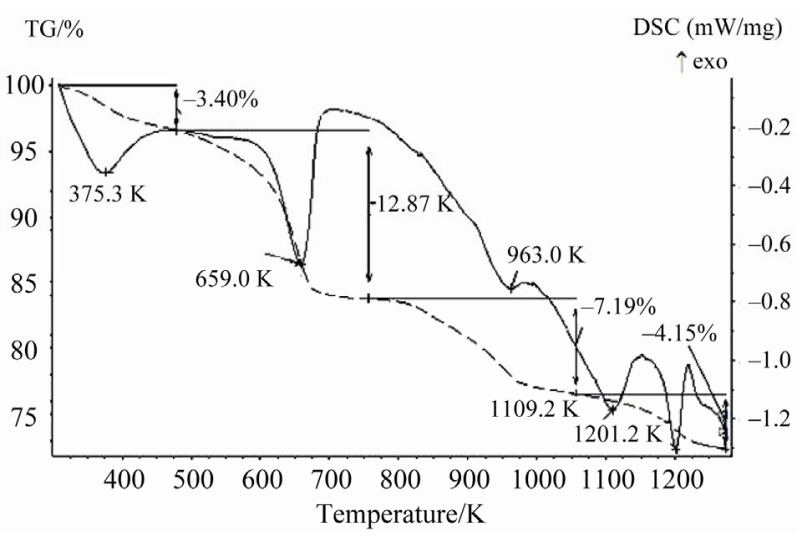

(a)

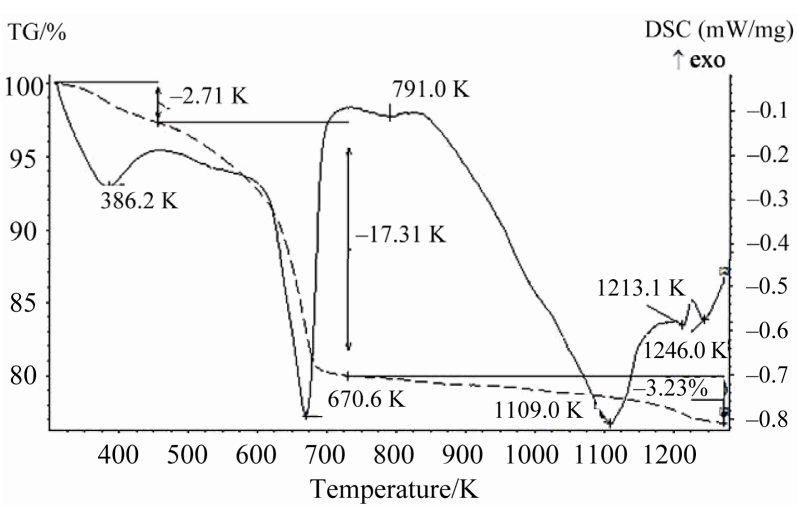

(b)

Figure 1. TG (dotted line) and DSC (solid line) curves of precipitated salt mixtures for $\mathrm{CdSnO}_{3}$ (a) and $\mathrm{Cd}_{2} \mathrm{SnO}_{4}$ (b) compositions.

in the range of 780 - $950 \mathrm{~K}$ (Figure 1(b)) is con- nected with powder sample keeping for a week before the experiment. It led to natural ageing of $\alpha-\mathrm{SnO}_{2} \cdot \mathrm{nH}_{2} \mathrm{O}$ in the sample and its turning into $\beta-\mathrm{SnO}_{2} \cdot \mathrm{nH}_{2} \mathrm{O}$. Gradual weight decrease at the temperature above $1150 \mathrm{~K}$ in both cases is caused by cadmium oxide sublimation. And also crystallization thermal effects can be observed under the same conditions.

The results of X-ray fluorescence analysis for samples at different stages treatment are presented in Table 1. As you can see, low-temperature samples correspond to the specific composition. Thermal treatment temperatures higher than $\sim 1000 \mathrm{~K}$ lead to substantial cadmium oxide evaporation and $\mathrm{Cd}$ : $\mathrm{Sn}$ molar ratio decreasing.

\subsection{X-Ray Phase Analysis of the Products}

Both Figure 2 and Table 2 show the XRD results for powder mixtures with a specific compositions which were annealed at different temperatures. The initial dried mixture consists of only crystal phase of cadmium carbonate. X-ray amorphous phase corresponding to tin (IV) oxide is present at the sample which was annealed at 
Table 1. Elemental composition (XRFA) of thermally treated powder mixtures.

\begin{tabular}{|c|c|c|c|}
\hline \multirow{2}{*}{ Annealing temperature, $\mathrm{K}$} & \multicolumn{2}{|c|}{ molar fraction of the element } & \multirow{2}{*}{ Cd:Sn ratio } \\
\hline & $\mathrm{Cd}$ & $\mathrm{Sn}$ & \\
\hline \multicolumn{4}{|c|}{$\mathrm{CdSnO}_{3}$ proper composition } \\
\hline Initial mixture & 0.49 & 0.51 & 0.97 \\
\hline $783 \mathrm{~K}$ & 0.49 & 0.51 & 0.97 \\
\hline $873 \mathrm{~K}$ & 0.49 & 0.51 & 0.97 \\
\hline $973 \mathrm{~K}$ & 0.48 & 0.52 & 0.94 \\
\hline $1073 \mathrm{~K}$ & 0.47 & 0.53 & 0.88 \\
\hline $1173 \mathrm{~K}$ & 0.46 & 0.54 & 0.86 \\
\hline $1223 \mathrm{~K}$ & 0.46 & 0.54 & 0.86 \\
\hline \multicolumn{4}{|c|}{$\mathrm{Cd}_{2} \mathrm{SnO}_{4}$ proper composition } \\
\hline Initial mixture & 0.66 & 0.34 & 1.96 \\
\hline $783 \mathrm{~K}$ & 0.66 & 0.34 & 1.96 \\
\hline $873 \mathrm{~K}$ & 0.66 & 0.34 & 1.96 \\
\hline $973 \mathrm{~K}$ & 0.66 & 0.34 & 1.96 \\
\hline $1073 \mathrm{~K}$ & 0.65 & 0.35 & 1.87 \\
\hline $1173 \mathrm{~K}$ & 0.64 & 0.36 & 1.77 \\
\hline $1223 \mathrm{~K}$ & 0.65 & 0.35 & 1.87 \\
\hline
\end{tabular}

$873 \mathrm{~K}$. These results confirm the data of thermal analysis. The CdO phase formation comes to an end up to $670 \mathrm{~K}$ according to TGA data. It is also confirmed by XRF analysis. The Quantitative phase contribution is conditional with the X-ray amorphous phase presence in the sample. Such values are marked with "*” in Table 2.

$\mathrm{XRF}$ analysis results of specific composition $\mathrm{Cd}_{2} \mathrm{SnO}_{4}$ mixtures are presented in both Figure 2(b) and Table 2. The phase of tin dioxide is possible to be registered in $\mathrm{Cd}_{2} \mathrm{SnO}_{4}$ system in contrast to $\mathrm{CdSnO}_{3}$ system. Starting from $873 \mathrm{~K}$ the samples contain both $\mathrm{CdSnO}_{3}$ and $\mathrm{Cd}_{2} \mathrm{SnO}_{4}$ cadmium stannates. As the temperature increases the comparative amount of metastannate slightly increases too. It seems to be connected with the increasing of volatile $\mathrm{CdO}$ velocity elimination. Orthostannate is presented by two modifications: they are cubic modification and orthorhombic one. However the content of orthorhombic modification exceeds $5 \%$ at the temperature over $973 \mathrm{~K}$ only.

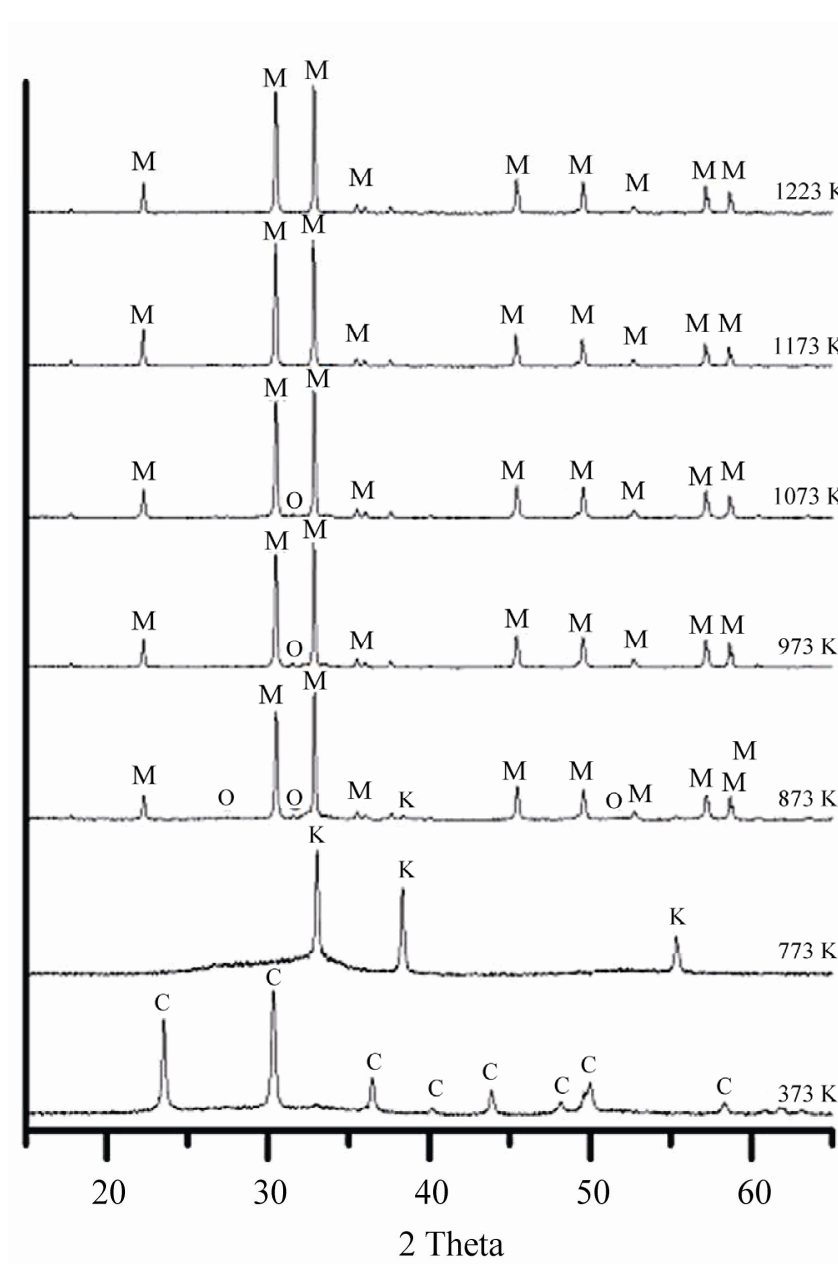

(a)

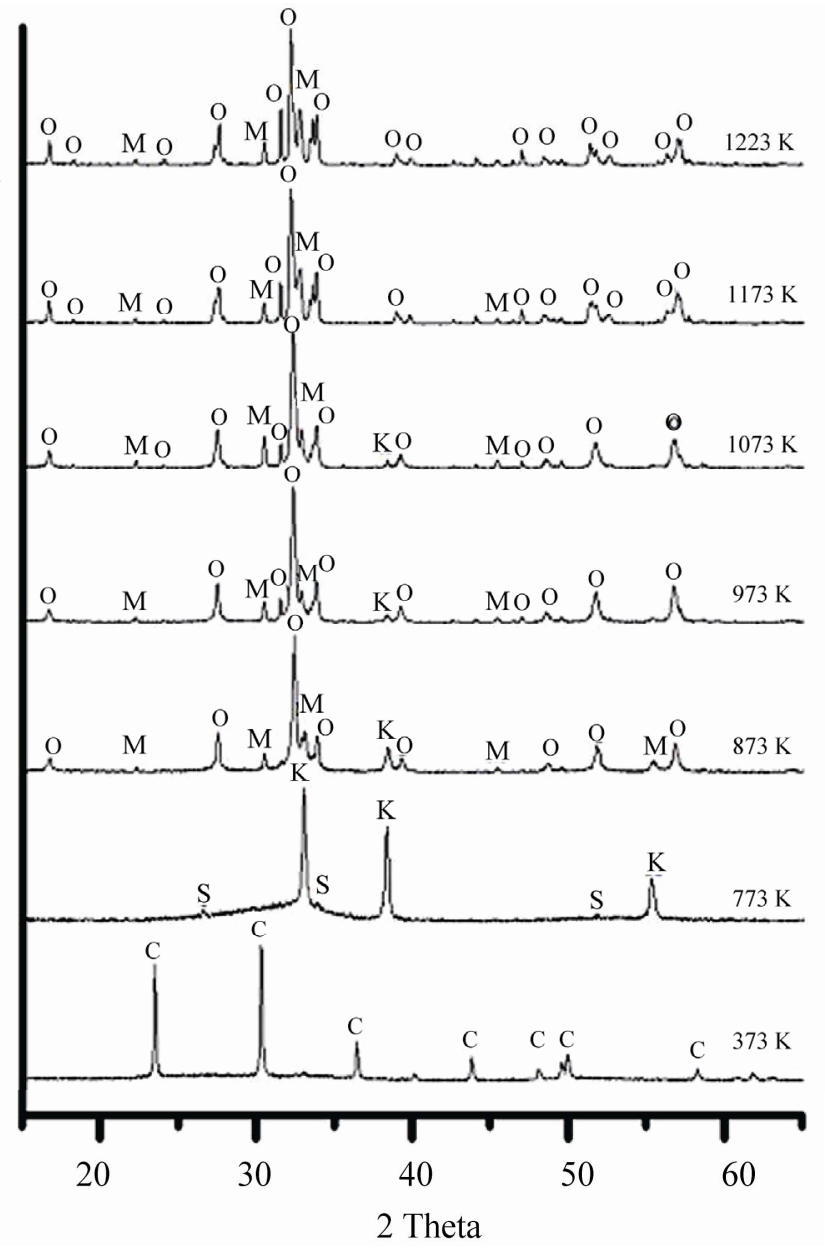

(b)

Figure 2. X-ray diffraction patterns of $\mathrm{CdSnO}_{3}$ (a) and $\mathrm{Cd}_{2} \mathrm{SnO}_{4}(\mathrm{~b})$ proper composition powder mixtures annealed at given temperatures: $\mathrm{O}-\mathrm{Cd}_{2} \mathrm{SnO}_{4}$ (cubic), $\mathrm{O}_{1}-\mathrm{Cd}_{2} \mathrm{SnO}_{4}$ (orthorhombic), $\mathrm{M}-\mathrm{CdSnO}_{3}, \mathrm{~K}-\mathrm{CdO}, \mathrm{C}-\mathrm{CdCO}_{3}, \mathrm{~S}-\mathrm{SnO}_{2}$. 
Table 2.Thermally treated powder mixtures composition (XRD).

\begin{tabular}{|c|c|c|c|c|c|c|}
\hline \multirow[b]{2}{*}{ Annealing temperature } & \multicolumn{6}{|c|}{ mass fraction } \\
\hline & $\mathrm{CdCO}_{3}$ & $\mathrm{CdO}$ & $\mathrm{SnO}_{2}$ & $\mathrm{CdSnO}_{3}$ & $\begin{array}{l}\mathrm{Cd}_{2} \mathrm{SnO}_{4} \\
\text { (cubic) }\end{array}$ & $\begin{array}{l}\mathrm{Cd}_{2} \mathrm{SnO}_{4} \\
\text { (orthorhombic) }\end{array}$ \\
\hline \multicolumn{7}{|c|}{$\mathrm{CdSnO}_{3}$ proper system } \\
\hline without annealing & $1 *$ & - & - & - & - & - \\
\hline $773 \mathrm{~K}$ & - & $1 *$ & - & - & - & - \\
\hline $873 \mathrm{~K}$ & - & 0.15 & - & 0.77 & - & 0.08 \\
\hline $973 \mathrm{~K}$ & - & - & - & 0.91 & - & 0.09 \\
\hline $1073 \mathrm{~K}$ & - & - & - & 0.99 & - & 0.01 \\
\hline $1173 \mathrm{~K}$ & - & - & 0.06 & 0.94 & - & - \\
\hline $1223 \mathrm{~K}$ & - & - & 0.05 & 0.91 & 0.04 & - \\
\hline \multicolumn{7}{|c|}{$\mathrm{Cd}_{2} \mathrm{SnO}_{4}$ proper system } \\
\hline without annealing & $1^{*}$ & - & - & - & - & - \\
\hline $773 \mathrm{~K}$ & - & $0.76^{*}$ & $0.24 *$ & - & - & - \\
\hline $873 \mathrm{~K}$ & - & 0.19 & - & 0.11 & 0.65 & 0.05 \\
\hline $973 \mathrm{~K}$ & - & 0.07 & - & 0.11 & 0.73 & 0.09 \\
\hline $1073 \mathrm{~K}$ & - & 0.08 & - & 0.13 & 0.71 & 0.08 \\
\hline $1173 \mathrm{~K}$ & - & - & - & 0.17 & 0.66 & 0.17 \\
\hline $1223 \mathrm{~K}$ & - & - & - & 0.16 & 0.66 & 0.18 \\
\hline
\end{tabular}

Shortage of cadmium oxide, comparatively to assigned stoichiometry of $\mathrm{CdSnO}_{3}$ and $\mathrm{Cd}_{2} \mathrm{SnO}_{4}$ compositions, is recorded in both involved systems in the samples at 1073 $\mathrm{K}$ and above what is caused by $\mathrm{CdO}$ sublimation. $\mathrm{CdO}$ loss in $\mathrm{Cd}_{2} \mathrm{SnO}_{4}$ system leads to phase composition change (Table 2) at the expense of $\mathrm{CdSnO}_{3}$ metastannate formation.

Thus specific compositions synthesis completes during an hour at $873 \mathrm{~K}$. In both cases the samples of the mixture contain some amount of $\mathrm{CdO}$ and improper stannate (Table 2).

The authors [9] studied of a cadmium stannates synthesis from prefabricated powders had evaluated phase ratios of $\mathrm{CdO}-\mathrm{SnO}_{2}$ and $2 \mathrm{CdO}-\mathrm{SnO}_{2}$ mixtures after sixhours-long annealing at the range 970 to $1420 \mathrm{~K}$ above. $\mathrm{Cd}_{2} \mathrm{SnO}_{4}$ appears in an equimolar mixture at about $970 \mathrm{~K}$. At $1170 \mathrm{~K}$ orthostannate is absolutely synthesized and $\mathrm{CdO}$ is used up. Metastannate forms at $1170 \mathrm{~K}$ above:

$$
\mathrm{Cd}_{2} \mathrm{SnO}_{4}+\mathrm{SnO}_{2}=2 \mathrm{CdSnO}_{3}
$$

This process finishes at about $1340 \mathrm{~K}$ and then $\mathrm{CdSnO}_{3}$ decomposes into $\mathrm{CdO}$ and $\mathrm{SnO}_{2} \cdot \mathrm{Cd}_{2} \mathrm{SnO}_{4}$ synthesis in $2 \mathrm{CdO}-\mathrm{SnO}_{2}$ mixture comes to an end at about $1320 \mathrm{~K}$. At $1320 \mathrm{~K}$ above $\mathrm{Cd}_{2} \mathrm{SnO}_{4}$ decomposes into $\mathrm{CdSnO}_{3}$ and CdO.

Thus long time and temperature of about $1300 \mathrm{~K}$ is necessary to synthesize both stannates from prefabricated powder components. Though the processes laws of stannates synthesis from coprecipitated salts confirm the observations given in the work [9], they require lower temperatures and shorter time for thermal treatment.

$\mathrm{Cd}_{2} \mathrm{SnO}_{4}$ and $\mathrm{CdSnO}_{3}$ obtaining in terms of individual phases requires the adjustment of firing regimes and formation of conditions preventing cadmium oxide vola- tilization. However practical application of such process of synthesis that gives the powder mixture with predominant content of proper cadmium stannates is possible e.g. in metalloxide electrocontact composites production when silver(copper)/oxide powder pressings sintering is combined with oxide phase synthesis. It provides high dispersion ability and statistical homogeneity of phase inclusions and also it does the production less power-consuming.

\subsection{Microscopy of Powder Products}

SEM-micropictures of $\mathrm{CdSnO}_{3}$ and $\mathrm{Cd}_{2} \mathrm{SnO}_{4}$ powders thermally treated at $1223 \mathrm{~K}$ are presented in Figure 3. We can see the likeness of microstructure and the morphology of particles when comparing. The powders are rather massive, loose, weakly bonded agglomerates, formed from crystal particles in the submicron range of dispersibility (from $\sim 50-100 \mathrm{~nm}$ to $1 \mu \mathrm{m}$ ).

\section{Conclusions}

The synthesis of $\mathrm{CdSnO}_{3}$ and $\mathrm{Cd}_{2} \mathrm{SnO}_{4}$ by thermal treatment of thermally unstable tin and cadmium compositions were carried out. It allows to obtain fine-grained products in the form of submicron sized powders with predominant content of proper stannates for short period of time under soft temperature conditions. Decomposition of salt mixture components carries in wide temperature range but cadmium meta- and orthostannates formation generally completes at $873 \mathrm{~K}$ already. In spite of powder products complicated structure which includes both of stannates and tin and cadmium oxides, the given powder synthesis method can be used for metalloxide composite materials "in-situ" synthesis in practice. With 


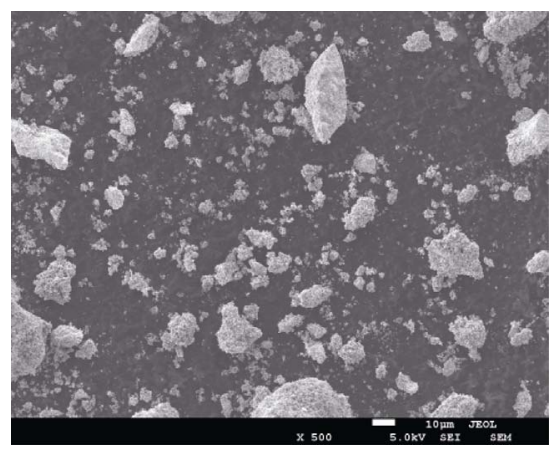

(a)

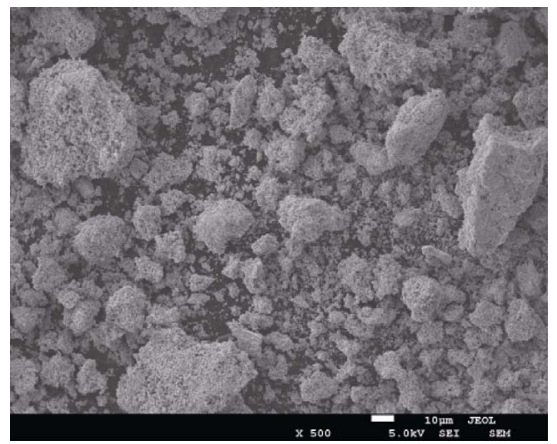

(c)

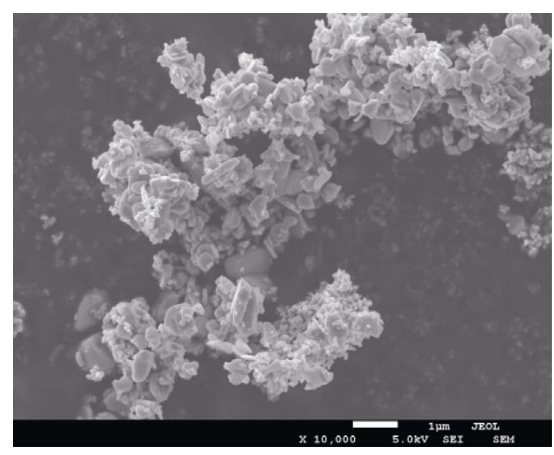

(b)

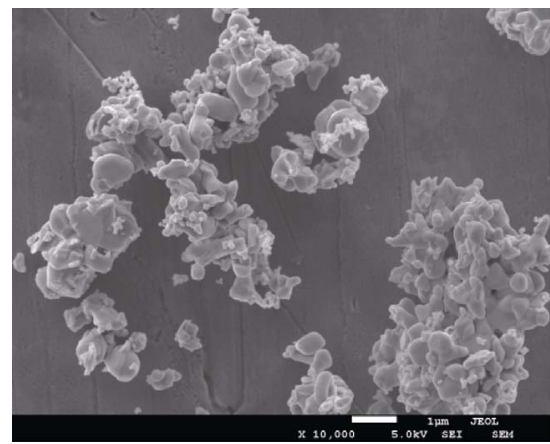

(d)

Figure 3. SEM-micropictures of $\mathrm{CdSnO}_{3}(\mathrm{a}, \mathrm{b})$ and $\mathrm{Cd}_{2} \mathrm{SnO}_{4}(\mathrm{c}, \mathrm{d})$ proper composition powders $(\mathrm{zoomed} \times 500$ and $\times 10000)$.

all this the technology is simplified substantially and time and energy charges for the production are reduced.

\section{Acknowledgements}

We would like to thank to Sergey D. Kirik and Galina M. Zeer for XRF and SEM measurements carrying out.

\section{REFERENCES}

[1] A. J. Nozik, "Optical and Electrical Properties of $\mathrm{Cd}_{2} \mathrm{SnO}_{4}$ : A Defect Semiconductor," Physical Review B, Vol. 6, No. 2, 1972, pp. 453-459. doi:10.1103/PhysRevB.6.453

[2] D. S. Ginley and C. Bright, "Transparent Conducting Oxides," Materials Research Society Bulletin, Vol. 25, 2000, pp.15-18.

[3] X. H. Wu, Y. D. Wang and Y. F. Li, "Electrical and GasSensing Properties of Perovskite-Type $\mathrm{CdSnO}_{3}$ Semiconductor Material," Materials Chemistry and Physics, Vol. 77, No. 2, 2002, pp. 588-593.

[4] T. S. Zhang, Y. S. Shen, R. F. Zhang and X. Q. Liu, "Ammonia-Sensing Characteristics of Pt-doped $\mathrm{CdSnO}_{3}$ Semiconducting Ceramic Sensor," Materials Letters, Vol. 27, No. 4-5, 1996, pp. 161-164.

[5] Y. L. Liu, Y. Xing, H. F. Yang, et al., "Ethanol Gas Sensing Properties of Nano-Crystalline Cadmium Stannate Thick Films Doped with Pt," Journal of Analytica Chimica Acta, Vol. 527, 2004, pp. 21-26. doi:10.1016/j.aca.2004.06.055

[6] V. Krishnakumar, K. Ramamurthi, R. Kumaravel, et al., "Preparation of Cadmium Stannate Films by Spray Pyrolysis Technique," Current Applied Physics, Vol. 9, 2009, pp. 467-471. doi:10.1016/j.cap.2008.04.006

[7] C. M. Ronconi, O. L. Alves and R. E. Bruns, "Factorial Design Preparation of Transparent Conducting Oxide Thin Films," Journal of Thin Solid Films, Vol. 517, 2009, pp. 2886-2891. doi:10.1016/j.tsf.2008.10.121

[8] Y. Tang, Y. Jiang, J. Bihui, et al., "Synthesis of $\mathrm{CdSnO}_{3} \cdot 3 \mathrm{H}_{2} \mathrm{O}$ Nanocubes via Ion Exchange and Their Thermal Decompositions to Cadmium Stannate," Journal of Inorganic Chemestry, Vol. 45, 2006, pp. 10774-10779. doi:10.1021/ic0613715

[9] F. Golestani-Fard, T. Hashemi, K. J. D. Mackenzie and C. A. Hogarth, "Formation of Cadmium Stannate by Electron Spectroscopy," Journal of Materials Science, Vol. 18, 1983, pp. $3679-3685$. doi:10.1007/BF00540740

[10] H. Mizoguchi, H. W. Eng and P. M. Woodward, "Probing the Electronic Structures of Ternary Perovskite and Pyrochlore Oxides Containing $\mathrm{Sn}^{+4}$ or $\mathrm{Sb}^{+5}$," Journal of Inorganic Chemistry, Vol. 43, 2004, pp. 1667-1680. doi:10.1021/ic034551c

[11] V. V. Ivanov, E. B. Antipov, A. M. Abakumov, et al., "Metal-Oxide Materials for Electrocontacts," Pat. RU 2367695, 20 September 2009. (Russian).

[12] F. Ya. Galahov, (Ed.), "Phase Diagrams of Refractory 
Oxides Systems. Handbook. Edition 5. Binary Systems," Part 1. Nauka, Leningrad, 1985, 284 Pages (Russian).

[13] D. R. Kammler, T. O. Mason and K. R. Poeppelmeier, "Phase Relationships, Transparency, and Conductivity in the Cadmium Indate-Cadmium Stannate System," Chemistry of Materials, Vol. 12, 2000, pp. 1954-1960. doi:10.1021/cm000101w

[14] D. Raviendra and J. K. Sharma, "Electroless Deposition of Cadmium Stannate, Zinc Oxide, and Aluminum-Doped Zinc Oxide Films," Journal of Applied Physics, Vol. 58,
No. 2, 1985, pp. 838-844. doi:10.1063/1.336310

[15] A. Askarinejad and A. Morsali, "Syntheses and Characterization of $\mathrm{CdCO}_{3}$ and $\mathrm{CdO}$ Nanoparticles by Using a Sonochemical Method," Materials Letters, Vol. 62, 2008, pp. 478-482. doi:10.1016/j.matlet.2007.05.082

[16] G. Brauer, "Handbook of Preparative Inorganic Chemistry," Academic Press, New York, 1965.

[17] R. A. Lidin, "Chemical Properties of Inorganic Matter," Kolos, Moscow, 2006, p. 480. 